\title{
REJEITOS DE MINERAÇÃO: UM OLHAR DO CENÁRIO BRASILEIRO - PARTE I: CADEIA PRODUTIVA*
}

\author{
Sandra Lúcia de Moraes ${ }^{1}$ \\ Flávia Gutierrez Motta² \\ Camila Peres Massola ${ }^{3}$ \\ Eduardo Maziero Saccoccio 4 \\ Marsis Cabral Júnior ${ }^{5}$
}

\section{Resumo}

O Brasil figura como uma das grandes potências minerais do mundo, sendo esse setor de grande valia para a economia brasileira por gerar milhares de empregos diretos e indiretos. Apesar de sua importância econômica e social, a atividade da mineração ocasiona uma grande geração de rejeitos. O país é detentor de um robusto arcabouço legal, com uma série de regulamentações a respeito do meio ambiente no setor mineral, sendo que 14 delas são específicas para rejeitos da mineração. No entanto, o acidente ocorrido com a barragem da Samarco em 2015 trouxe novamente à pauta a temática dos rejeitos, o que tem instigado uma série de discussões na cadeia da mineração. Neste trabalho, os autores procuraram caracterizar três aspectos: o cenário atual da cadeia produtiva da mineração, a problemática da geração de rejeitos e o nível de desenvolvimento tecnológico que visa o seu aproveitamento. Esse conteúdo está estruturado em duas partes. A primeira parte, retratada neste documento, analisa a cadeia produtiva da mineração e a dinâmica que caracteriza a participação de seus vários atores, assim como as formas de aumentar os investimentos em processos de recuperação de rejeitos.

Palavras-chave: Mineração; Cadeia Produtiva; Rejeitos

\section{MINING TAILINGS: A PERSPECTIVE OF THE BRAZILIAN SCENARIO - PART I: VALUE CHAIN}

\section{Abstract}

Brazil is one of the major world mining countries. The mining sector is of great importance to the Brazilian economy because it is responsible for thousands of job vacancies. Despite its economic and social relevance, the mining activity also generates an enormous amount of tailings. Brazil's regulatory framework on the environmental issues related to the mining sector is strong, and 14 of those regulations specifically concern mining tailings. The Samarco's dam spill, which occurred in 2015, brought light to the issue of mining tailings, raising a number of questions in the mineral value chain. In this work, the authors provide a picture of the Brazilian mineral production chain, its tailings generation as well as the level of technological development aimed at the reuse of such tailings. The work is structured in two parts. This document highlights the mineral value chain in Brazil and the dynamics of its stakeholders. In addition, it discusses ways of increasing investments in the processes of recovery of mineral tailings.

Keywords: Mining; Value chain; Tailings.

1 Membro da ABM, Engenheiro Químico, Doutor em Ciências, Resp. pelo Laboratório de Processos Metalúrgicos, Instituto de Pesquisas Tecnológicas do Estado de São Paulo, São Paulo - SP, Brasil.

2 Doutor em Engenharia de Produção, Gerente de Planejamento e Negócios do IPT - Instituto de Pesquisas Tecnológicas do Estado de São Paulo, São Paulo - SP, Brasil.

3 Engenheiro de Minas, Doutor em Ciências, Pesquisador, Instituto de Pesquisas Tecnológicas do Estado de São Paulo, São Paulo - SP, Brasil.

4 Engenheiro Químico, Pesquisador, Instituto de Pesquisas Tecnológicas do Estado de São Paulo, São Paulo - SP, Brasil.

5 Geólogo, Doutor em Geociências, Pesquisador, Instituto de Pesquisas Tecnológicas do Estado de São Paulo, São Paulo - SP, Brasil.. 


\section{INTRODUÇÃO}

Os bens minerais são componentes essenciais de grande parte dos produtos utilizados pela sociedade moderna, tendo um papel fundamental tanto para a economia quanto para a população. Para manter o padrão de vida da sociedade, cada brasileiro consome anualmente (Quadro 1) cerca de 5,4 toneladas de insumos de origem mineral. Considerando uma expectativa de vida de 70 anos, esse consumo alcança 328 toneladas, sendo que para obtenção desses materiais são gerados 3.000 t de rejeitos por habitante [1].

Quadro 1. Consumo anual de insumo de origem mineral por habitante.

\begin{tabular}{lc}
\hline Insumo & Consumo anual por habitante $(\mathbf{k g})$ \\
\hline Aço & 116 \\
Alumínio & 8,3 \\
Cobre & 1,9 \\
Manganês & 1,5 \\
Ouro & 0,29 \\
Zinco & 1,29 \\
Outros metais & 4,0 \\
Fertilizantes & 27 \\
Areia+brita & 3700 \\
Cimento & 320 \\
Argila & 1.220 \\
Vidro & 8,75 \\
Gesso & 18 \\
\hline Fonte: Elaborado pelos autores com informações de Araújo [1].
\end{tabular}

Segundo a National Research Council [2], nos anos 1980 eram necessários 12 elementos químicos para fabricar um chip, quantidade que subiu para 16 na década seguinte e, atualmente, são necessários 60 elementos para produzir um chip de alto rendimento. Esse padrão se repete se avaliarmos os automóveis e outros produtos que passaram a incorporar eletrônicos como componentes de seus sistemas. Portanto, o padrão atual de consumo é altamente dependente da atividade mineral e, quanto maior a renda per capita do país, maior é essa dependência.

Para a economia brasileira é inegável a importância do setor mineral. A sua cadeia compreende as etapas de geologia, mineração e transformação mineral e é base para diversas outras cadeias produtivas.

A magnitude da dotação mineral brasileira é traduzida na produção de mais de 50 substâncias minerais, atingindo em 2014 o valor de US\$ 40 bilhões, o que correspondeu a $5 \%$ do PIB industrial do país. Além disso, naquele mesmo ano, o setor foi responsável pela geração de 214.000 empregos diretos. Pelos encadeamentos a jusante e a montante na cadeia produtiva mínero-industrial, estima-se que o efeito multiplicador seja da ordem de 13 empregos indiretos ou induzidos, representando cerca de 2,7 milhões de trabalhadores [3].

A despeito da grande importância social e econômica da mineração para o país, uma externalidade negativa inerente a esta atividade é a geração de resíduos sólidos. Dispostos geralmente em pilhas e barragens, as grandes minas ou áreas com adensamento de minerações mobilizam áreas relativamente extensas junto às frentes de lavra e plantas de beneficiamento.

Dessa forma, o aproveitamento de rejeitos bem como a diminuição da sua geração constitui tendência irreversível para o setor mineral. Como apontado por Salles e Costa [4], a percepção de sua relevância deverá conduzir a visão estratégica sobre o tema, vindo a constituir um conjunto de oportunidades de mínero-negócios sistêmicos, a partir de uma nova perspectiva de atuação empresarial nos territórios e, consequentemente, na sociedade em geral. 
O presente trabalho procurou trazer uma reflexão sobre o cenário atual da cadeia produtiva da mineração, a questão da geração de resíduos e o nível de desenvolvimento tecnológico voltado para aproveitamento desses rejeitos. Os dados levantados geraram uma série de informações que foram estruturadas em duas partes. A Parte I, escopo desse documento, apresenta uma visão geral da cadeia produtiva da mineração e a dinâmica que caracteriza a atuação dos vários atores que a compõem, em especial relacionados à questão da geração e recuperação dos rejeitos. A Parte II está apresentada em outro documento e aborda o estágio atual de desenvolvimento tecnológico com vistas ao aproveitamento de rejeitos de mineração: novos usos para esses materiais e desafios impostos à indústria nesse contexto.

\section{MATERIAIS E MÉTODOS}

As principais atividades desenvolvidas procuraram levantar informações para:

- quantificar a geração de rejeitos de mineração no Brasil;

- identificar os atores envolvidos na cadeia produtiva mineral de mineração e de recuperação de rejeitos (ICTs públicas e privadas, empresas mineradoras, empresas de equipamentos e fornecedores de insumos);

- compreender os fatores determinantes da dinâmica do setor de mineração.

Para atingir os objetivos desse artigo buscou-se:

- informações secundárias com base em estudos setoriais e em publicações de associações e entidades representativas da indústria para quantificar a geração de rejeitos e identificar os atores relevantes da cadeia produtiva míneroindustrial;

- entrevistas com especialistas do setor e entidades representativas para caracterizar a dinâmica do setor e pontuar sobre o desafio do tratamento e recuperação dos rejeitos.

\section{RESULTADOS E DISCUSSÃO}

\subsection{A Indústria Mineral no Brasil}

Fatores como a extensão territorial de dimensões continentais e a expressiva geodiversidade, caracterizada por uma variedade de ambientes geológicos propícios a uma grande gama de mineralizações, conferem ao Brasil rica dotação mineral, equiparando-o às grandes potências minerais globais.

As reservas brasileiras dos minérios metálicos de nióbio, tântalo, terras raras, níquel, manganês, estanho, alumínio, e ferro assumem expressão no cenário mundial. Para os minerais industriais, se sobressaem as reservas de grafita, barita, vermiculita, magnesita, além de talco e pirofilita. Quanto à produção, o Brasil tem participação relevante nos mercados de nióbio, bauxita, ferro, tantalita, estanho, manganês, grafita, magnesita, crisotila, vermiculita, talco e pirofilita, além de grafita natural e rochas ornamentais. A Figura 1 apresenta a evolução da Produção Mineral Brasileira (PMB) a partir de 1994, em bilhões de dólares.

A partir de 2011, quanto atingiu seu máximo de US\$ 53 bilhões, a PMB foi fortemente afetada pela depreciação das commodities minerais, principalmente em função da queda acentuada de preço do minério de ferro, sendo que em quantidade a produção não se alterou de forma significativa. 


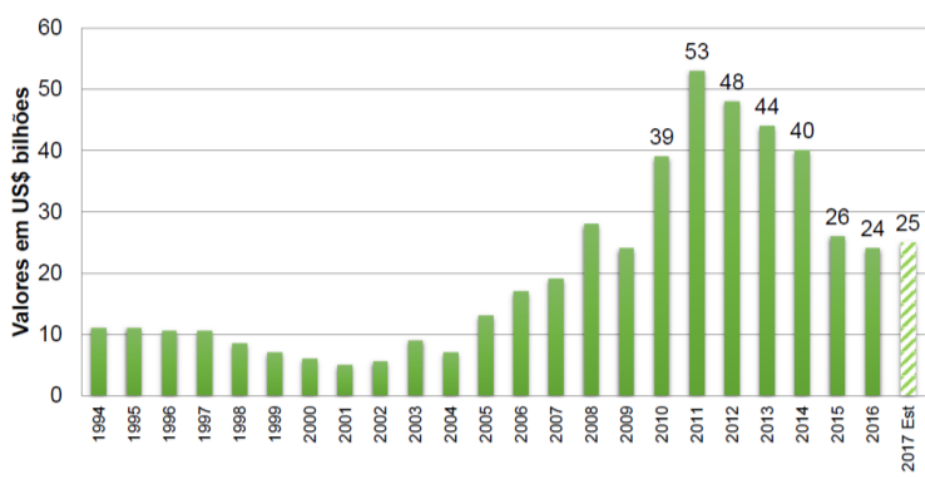

Figura 1 - Produção mineral brasileira - valores em US\$ (não inclui petróleo e gás).

Fonte: IBRAM [5]

Quanto às exportações, que totalizaram US\$ 34,3 bilhões em 2014, o grande destaque é para o minério de ferro (US\$25,8 bilhões - $75 \%$ do total), seguido de longe por ouro, cobre, rochas ornamentais, entre outros. Para as importações, em 2014, a dependência de bens primários alcançou o valor de US $\$ 7,8$ bilhões, concentrando-se no potássio, carvão mineral, cobre, enxofre, rocha fosfática e zinco. No curto e médio prazo, não há perspectiva de aumento substancial na produção dos dois primeiros bens minerais (potássio e carvão mineral), que devem continuar no topo da pauta de importações minerais brasileiras.

A produção mineral do país é proveniente de 8.870 empresas de mineração [3], das quais 515 estão localizadas na região Norte, 1.606 no Nordeste, 1.075 no CentroOeste, 3.609 no Sudeste e 2.065 na região Sul. Os empreendimentos apresentam características heterogêneas quanto ao volume de extração, produtividade, grau de mecanização e uso de tecnologias de lavra e beneficiamento, bem como com relação ao controle ambiental dos empreendimentos. Do total de 8.400 minas em atividade catalogadas [3], 82,5 \% correspondem a minerações de micro e pequeno porte (Figura 2).

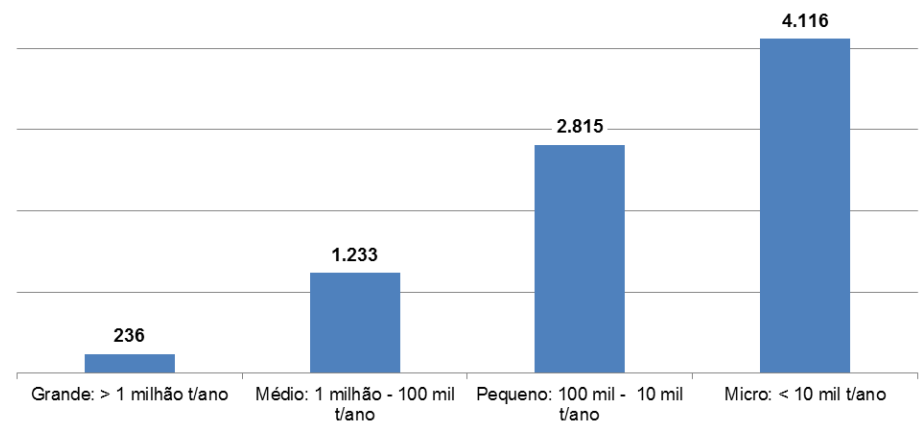

Figura 2. Porte das minas em atividade no Brasil. Fonte: IBRAM [3].

Em termos de estrutura de mercado, o setor de mineração é caracterizado pela presença de monopólios (como no caso do nióbio) e oligopólios (como minério de ferro, bauxita, zinco, entre outros) e uma estrutura heterogênea com grande número de empresas que atuam regionalmente, melhor representada pelos minerais relacionados à construção civil (areia e rocha britada).

\subsection{A Mineração e a Geração de Rejeitos}

Uma das características marcantes da indústria mineral refere-se aos expressivos volumes de massas de materiais removidos e movimentados a partir das áreas 
mineradas. Do montante extraído das minas, apenas uma parcela resulta no produto mineral destinado aos setores intermediários (indústria de transformação) ou final de consumo (construção civil). Volumes consideráveis de materiais sólidos não aproveitados economicamente são gerados a partir da atividade de mineração, constituindo-se em resíduos, e classificados como estéreis e rejeitos.

Os estéreis são os materiais escavados sem valor econômico, individualizados no processo de lavra, correspondendo às camadas sobrejacentes ou intercaladas ao corpo do minério. Já os rejeitos de mineração, foco do presente trabalho, resultam do processo de beneficiamento a que o minério é submetido, em que são retiradas as impurezas (ganga) para aumentar a qualidade ou teor do bem mineral, ou quando se busca padronizar o produto (separação de rocha britada e areia por tamanho).

Três principais fatores determinam o volume de resíduos gerados em uma mina. Os dois primeiros estão diretamente vinculados à natureza da jazida, envolvendo a localização do corpo mineralizado em relação à superfície e a concentração do mineral de minério contido. O terceiro está relacionado ao processo de lavra e beneficiamento empregado. Portanto, para um mesmo tipo de substância mineral, dependendo da forma de ocorrência, dos teores e das tecnologias de lavra e beneficiamento empregadas, serão geradas diferentes quantidades de resíduos.

A quantificação dos volumes de rejeito de mineração foi estimada a partir dos dados do Anuário Mineral Brasileiro (2001 a 2010) e do Sumário Mineral (2010 a 2014), ambos elaborados pelo DNPM. Como inexiste uma base consolidada para apuração da geração de rejeitos de mineração no Brasil, considerou-se razoável adotar que a quantidade de rejeitos seja obtida pela diferença entre as produções bruta (ROM) e beneficiada das substâncias minerais. Essa mesma metodologia já fora adotada num estudo do IPEA [6]. A Tabela 1 apresenta a estimativa do montante de rejeitos gerados com base nos dados do último Anuário Mineral (2010) [7].

Tabela 1. Rejeitos de mineração gerados de acordo com o Anuário Mineral (2010) - ano-base 2009.

\begin{tabular}{|c|c|c|c|c|c|}
\hline Substância & Rejeito (t) & Rejeito (\%) & Substância & Rejeito (t) & Rejeito (\%) \\
\hline Ouro & 187.084 .922 & 100,0 & Areias Industriais & 1.609 .506 & 24,6 \\
\hline Ferro & 108.544 .631 & 26,7 & Manganês & 1.594 .868 & 37,3 \\
\hline Cobre & 36.875 .893 & 97,9 & Prata & 1.564 .571 & 100,0 \\
\hline Fosfato & 31.465 .502 & 85,3 & Gipsita & 1.542 .583 & 65,7 \\
\hline Titânio & 23.946 .407 & 99,6 & Zinco & 1.375 .366 & 76,9 \\
\hline Estanho & 15.736 .682 & 99,9 & Talco e outras Cargas Minerais & 1.310 .910 & 38,3 \\
\hline Areia & 13.261 .366 & 5,0 & Grafita & 1.131 .340 & 95,0 \\
\hline Alumínio & 12.470 .862 & 33,8 & Chumbo & 675.431 & 97,7 \\
\hline Zircônio & 11.871 .565 & 99,8 & Cromo & 614.587 & 62,8 \\
\hline Nióbio & 11.610 .074 & 97,4 & Tântalo & 560.353 & 83,5 \\
\hline Calcário & 8.426 .234 & 7,7 & Monazita e Terras-Raras & 361.931 & 99,9 \\
\hline Carvão Mineral & 7.328 .636 & 55,9 & Tungstênio & 191.322 & 99,8 \\
\hline $\begin{array}{l}\text { Rochas (Britadas) e } \\
\text { Cascalho }\end{array}$ & 5.859 .001 & 2,5 & Urânio e outros Radioativos & 169.878 & 99,8 \\
\hline Bário & 4.515 .770 & 98,9 & $\begin{array}{l}\text { Feldspato, Leucita e Nefelina- } \\
\text { Sienito }\end{array}$ & 107.721 & 29,9 \\
\hline Amianto & 4.419 .851 & 93,9 & Vermiculita e Perlita & 105.564 & 68,6 \\
\hline Caulim & 4.157 .539 & 68,7 & Fluorita e Criolita & 90.241 & 68,4 \\
\hline Níquel & 4.140 .169 & 95,5 & Lítio & 27.364 & 64,5 \\
\hline $\begin{array}{l}\text { Dolomito e } \\
\text { Magnesita }\end{array}$ & 3.796 .425 & 73,8 & Mica & 8.384 & 31,1 \\
\hline Cobalto & 3.157 .993 & 98,8 & Diatomita & 3.338 & 44,4 \\
\hline Enxofre & 2.013 .836 & 81,9 & $\begin{array}{l}\text { Cianita e outros minerais } \\
\text { refratários }\end{array}$ & 6 & 0,4 \\
\hline Potássio & 1.827 .772 & 71,8 & Total & 515.556.394 & 35,5 \\
\hline
\end{tabular}

Fonte: elaborado pelos autores com dados do Anuário Mineral [7]. 
A partir da Tabela 1, constata-se que em 2009 a relação mássica entre a quantidade de rejeitos gerados sobre o montante de minério extraído foi de 35,5\%. Nove substâncias minerais, todas metálicas, geram individualmente mais de 10 milhões de toneladas anuais de rejeitos cada: ouro, ferro, cobre, fosfato, titânio, estanho, alumínio, zircônio e nióbio. Em conjunto, essas substâncias são responsáveis pela geração de 439,6 milhões de toneladas de rejeito, ou 85,3 \% do total.

Para estimar a quantidade acumulada de rejeitos da mineração entre 2000 a 2014, selecionou-se 15 substâncias minerais dentre as cerca de 70 produzidas no país, seguindo o critério já adotado nos estudos de IPEA [6]. Essas 15 principais substâncias correspondem a aproximadamente $90 \%$ da produção total bruta de minerais em massa [7], caracterizando-se também como as mais importantes geradoras de rejeito. Além desse critério, foi considerado para a seleção o potencial de toxicidade desses materiais e a disponibilidade de informações para 0 diagnóstico. A quantidade acumulada de rejeitos foi calculada com base no método descrito no Quadro 2.

Quadro 2. Método para estimar o volume de geração de rejeitos - 2000 a 2014.

\begin{tabular}{|c|c|c|c|c|}
\hline Período & $R O M$ & Produção beneficiada & Volume rejeitos & Índice de rejeito \\
\hline $\begin{array}{l}2000- \\
2009\end{array}$ & $\begin{array}{l}\text { Anuário Mineral } \\
\text { Brasileiro }\end{array}$ & $\begin{array}{l}\text { Anuário Mineral } \\
\text { Brasileiro }\end{array}$ & $\begin{array}{l}\text { Volume de rejeito = ROM - } \\
\text { produção beneficiada }\end{array}$ & $\begin{array}{l}\text { Volume de } \\
\text { rejeitos/ROM }\end{array}$ \\
\hline $\begin{array}{l}2010- \\
2014\end{array}$ & Sumário Mineral & Sem informação & $\begin{array}{l}\text { Volume de rejeito }=\mathrm{ROM} \text { * } \\
\text { índice de rejeito obtido do } \\
\text { período } 2000 \text { a } 2009\end{array}$ & $\begin{array}{l}=\text { período } 2000 \mathrm{a} \\
2009\end{array}$ \\
\hline
\end{tabular}

As estimativas do volume de rejeitos para os anos de 2010 a 2014 consideraram os dados disponíveis no Sumário Mineral, que dispõe de informações sobre um grupo reduzido de substâncias minerais, não apresentando valores para a produção beneficiada. Nesse caso, para as inferências a partir de 2010, foi considerada 0 índice de rejeito do período de 2000 a 2009, multiplicado pelos respectivos valores anuais de ROM obtidos pelo Sumário Mineral. Como o calcário não está computado nas estatísticas do Sumário Mineral, a partir de 2010 foi estabelecido um valor anual fixo similar ao volume de rejeito gerado em 2009.

Esse procedimento permitiu atualizar os dados da geração de rejeitos de mineração, mas se trata de uma estimativa, pois fica evidente que eventuais otimizações para diminuição de geração de rejeitos não estão consideradas.

A quantidade acumulada de rejeitos de mineração no período 2000 a 2014 está apresentada na Figura 3, em valores absolutos (Mt) e em porcentagem, por substância mineral.

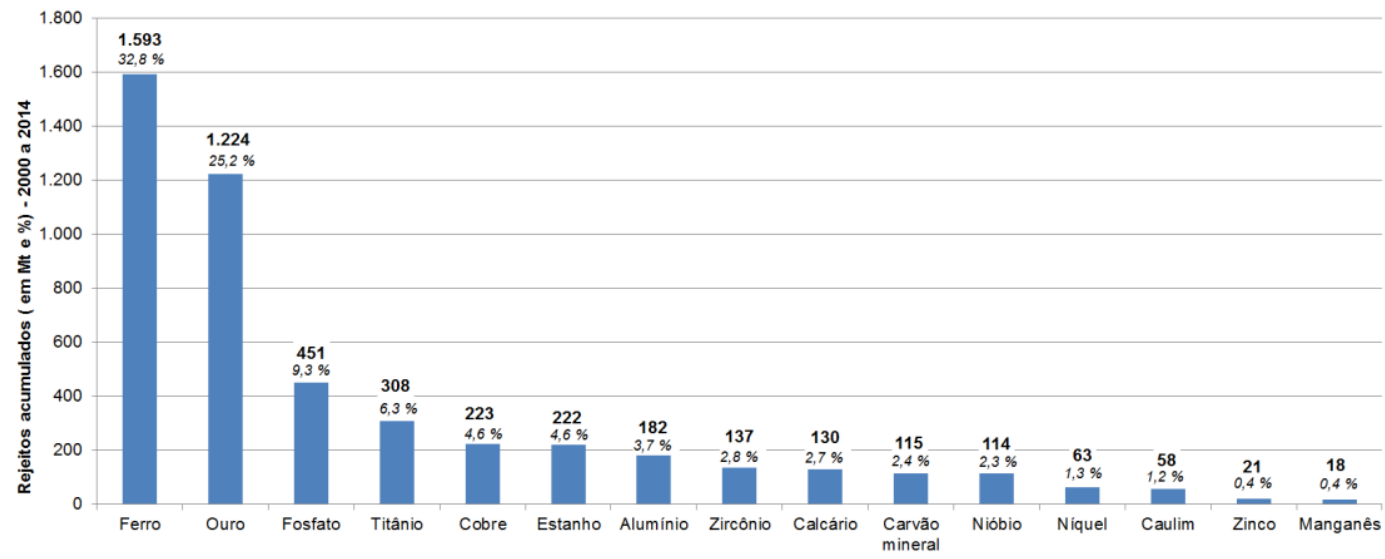

Figura 3. Quantidade acumulada de rejeitos de mineração de 2000 a 2014 (15 substâncias selecionadas). 
No período considerado, estima-se que foram acumulados cerca de 4,86 bilhões de toneladas de rejeitos, sendo que as produções de minério de ferro, ouro e fosfato superaram individualmente o patamar de um bilhão de toneladas, e que apenas os dois primeiros representam $58 \%$ do total de rejeitos gerados.

Os dados do Cadastro Nacional de Barragens de Mineração [8] foram analisados para contribuir com o entendimento da distribuição da estocagem de rejeitos no cenário brasileiro atual envolvendo as barragens de rejeitos da mineração. No cadastro, foram identificadas 199 empresas responsáveis por 661 barragens. Doze substâncias minerais têm mais de 10 barragens cada, totalizando 92,4\% dos barramentos, e a maioria das barragens (42,3 \%) está associada à produção de minério de ferro (Figura 4). As barragens estão localizadas em 19 unidades federativas (Figura 5). Os destaques são Minas Gerais, que concentra $48 \%$ das barragens cadastradas, seguido por São Paulo com 11 \% e Pará com 10 \%.

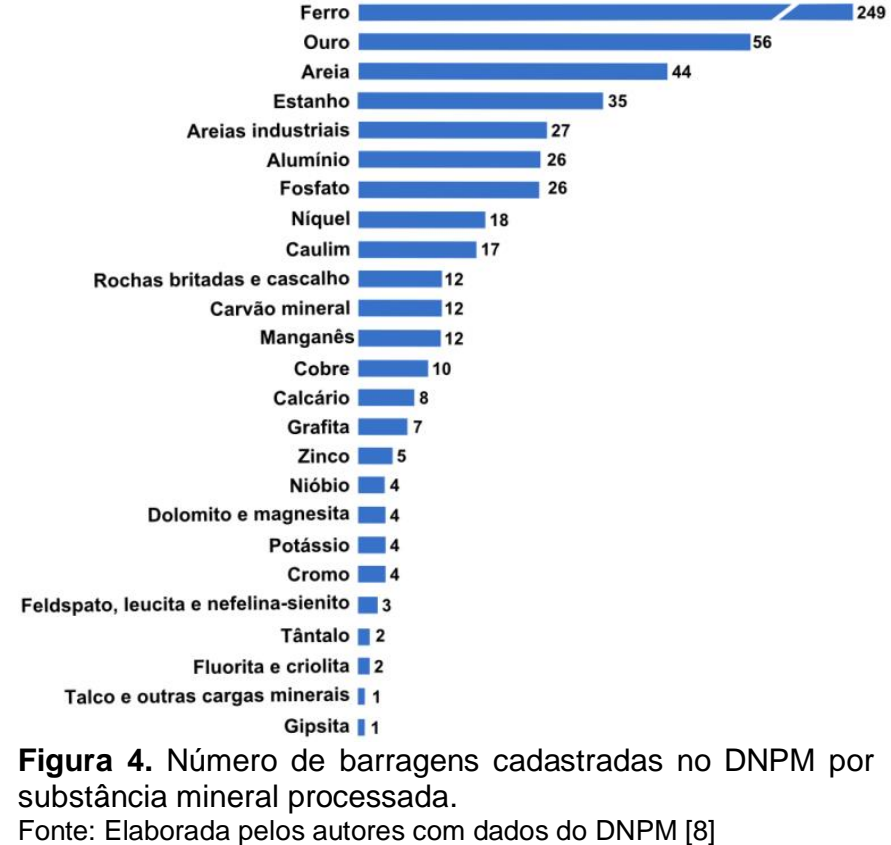

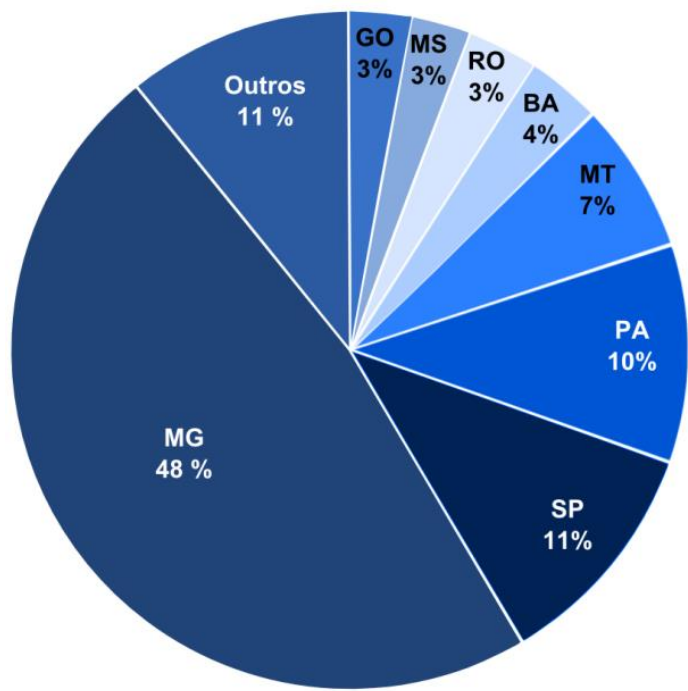

Figura 5. Distribuição de barragens por unidade da federação (\%). Fonte: Elaborada pelos autores com dados do DNPM [8]

\subsection{Regulação do setor}

O rompimento da barragem do Fundão da Mineradora Samarco, em 5 de novembro de 2015 em Mariana - MG, trouxe à tona o assunto rejeitos da mineração e seus impactos ambientais e sociais. A legislação que regulamenta o setor tornou-se assunto nos mais diferentes ambientes - acadêmico, empresarial, governamental com o objetivo principal de identificar mudanças e melhorias para criação de novas regulamentações de maneira a evitar novas tragédias como a de Mariana.

Estudo realizado pelo IPEA [6] levantou uma série de legislações relacionadas a resíduos sólidos no setor de mineração, contemplando os principais artigos que constituem o arcabouço legal contido na Constituição Federal de 1988; as legislações federais relacionadas ao meio ambiente no setor mineral até o ano de 2010; as resoluções do Conselho Nacional do Meio Ambiente (Conama) e do Conselho Nacional de Recursos Hídricos $(\mathrm{CNRH})$; as portarias e resoluções de outros órgãos federais; e as normas da ABNT relacionadas ao meio ambiente no setor mineral. No total, aquele estudo identificou 13 artigos da Constituição, 44 decretos, 22 leis, 20 resoluções do Conama, 4 portarias e resoluções de outros órgãos e 37 normas da ABNT, todas relacionadas ao meio ambiente no setor mineral. 
O tema rejeitos da mineração, mais especificamente, destaca-se nas leis № 12.305 , de 2 de Agosto de 2010 que institui a Política Nacional de Resíduos Sólidos e na Lei № 12.334, de 20 de Setembro de 2010 que estabelece a Política Nacional de Segurança de Barragens. Porém, cabe ressaltar que há ainda uma série de decretos, portarias, normas e resoluções que contribuem complementarmente para a regulamentação da questão dos rejeitos do setor.

O presente trabalho revisou e ampliou o levantamento do IPEA [6], apresentando no Quadro 3 os principais marcos regulatórios que não constam no levantamento inicial do IPEA e são relacionados ao tema rejeitos da mineração até meados de 2017.

Quadro 3. Marcos regulatórios relacionados ao tema rejeitos da mineração.

\begin{tabular}{|c|c|c|}
\hline LEGISLAÇÃO & ANO & DESCRIÇÃO \\
\hline Portaria DNPM nº 70.389 & 2017 & $\begin{array}{l}\text { Cria o Cadastro Nacional de Barragens de Mineração, o Sistema Integrado de Gestão } \\
\text { em Segurança de Barragens de Mineração e estabelece a periodicidade de execução } \\
\text { ou atualização, a qualificação dos responsáveis técnicos, o conteúdo mínimo e o nível } \\
\text { de detalhamento do Plano de Segurança da Barragem, das Inspeções de Segurança } \\
\text { Regular e Especial, da Revisão Periódica de Segurança de Barragem e do Plano de } \\
\text { Ação de Emergência para Barragens de Mineração. }\end{array}$ \\
\hline Portaria DNPM nำ14 & 2016 & $\begin{array}{l}\text { Estabelece prazo para apresentação de comprovante de entrega das cópias físicas do } \\
\text { Plano de Ação de Emergência de Barragem de Mineração (PAEBM) }\end{array}$ \\
\hline Decreto $n \div 46.933$ & 2016 & Institui a Auditoria Técnica Extraordinária de Segurança de Barragem \\
\hline $\begin{array}{ll}\text { Resolução } & \text { Conjunta } \\
\text { SEMAD/FEAM no } 2372 & \end{array}$ & 2016 & $\begin{array}{l}\text { Estabelece diretrizes para realização da auditoria extraordinária de segurança de } \\
\text { barragens de rejeito e para a emissão da correspondente Declaração Extraordinária de } \\
\text { Condição de Estabilidade. }\end{array}$ \\
\hline Portaria DNPM n 526 & 2013 & $\begin{array}{l}\text { Estabelece a periodicidade de atualização e revisão, a qualificação do responsável } \\
\text { técnico, o conteúdo mínimo e o nível de detalhamento do Plano de Ação de } \\
\text { Emergência das Barragens de Mineração (PAEBM).(Revogada pela Portaria DNPM no } \\
70.389 \text { ) }\end{array}$ \\
\hline Resolução CNRH n 143 & 2012 & Estabelece critérios de classificação de barragens (risco, dano potencial e volume) \\
\hline Resolução DNPM nº 144 & 2012 & Diretrizes para implementação da Política Nacional de Segurança de Barragens \\
\hline Portaria DNPM № 416 & 2012 & $\begin{array}{l}\text { Cria o Cadastro Nacional de Barragens de Mineração e dispõe sobre o Plano de } \\
\text { Segurança, Revisão Periódica de Segurança e Inspeções Regulares e Especiais de } \\
\text { Segurança das Barragens de Mineração. (Revogada pela Portaria DNPM no 70.389) }\end{array}$ \\
\hline Decreto $n^{\circ} 7.404$ & 2010 & $\begin{array}{l}\text { Cria o Comitê Interministerial da Política Nacional de Resíduos Sólidos e o Comitê } \\
\text { Orientador para a Implantação dos Sistemas de Logística Reversa. }\end{array}$ \\
\hline $\begin{array}{l}\text { Deliberação Normativa COPAM } \\
n^{\circ} 124\end{array}$ & 2008 & Complementa a Deliberação Normativa COPAM nº 87 \\
\hline $\begin{array}{l}\text { Deliberação Normativa COPAM } \\
n^{0} 87\end{array}$ & 2005 & Altera e complementa a Deliberação Normativa COPAM n 62 \\
\hline Resolução do CONAMA n 303 & & Dispõe sobre parâmetros, definições e limites de áreas de Preservação Permanente. \\
\hline $\begin{array}{l}\text { Deliberação Normativa COPAM } \\
\mathrm{n}^{0} 62\end{array}$ & & Dispõe sobre critérios de classificação de barragens de contenção de rejeitos \\
\hline Portaria DNPM n 237 & & Aprova as Normas Reguladoras de Mineração - NRM \\
\hline
\end{tabular}

Fonte: Elaborado pelos autores a partir de levantamento próprio e de dados do IPEA [6].

\subsection{Análise de ações de empresas e governo no tema rejeitos da mineração}

O acidente ocorrido em Mariana - MG promoveu a discussão a respeito da legislação vigente e estimulou as empresas e governos a adotarem ações e divulgarem com maior força os esforços e resultados de projetos de inovação e de minimização de geração/recuperação de rejeitos. Individualmente ou em conjunto com suas associações as empresas têm divulgado projetos de redução de consumo de energia, diminuição de uso de água nos processos e de disposição dos rejeitos. Destarte, cabem ser destacados alguns projetos realizados por grandes empresas geradoras de grandes volumes de rejeitos (Quadro 4). Em relação a ações realizadas pelos governos, destacam-se os casos colocados no Quadro 5. 
Quadro 4. Ações de algumas empresas no tema rejeitos de mineração.

\begin{tabular}{|c|c|c|c|}
\hline Empresa & Ações & Objetivo & Referência \\
\hline Vale (Carajás) & Projeto SD11 Elizer Batista & $\begin{array}{l}\text { Minério de ferro de alta qualidade } \\
\text { Aumento da vida útil da mina } \\
\text { Economia do consumo de diesel } \\
\text { (transporte truckless) } \\
\text { Dispensa de uso de água } \\
\text { (beneficiamento em umidade natural) }\end{array}$ & [9] \\
\hline $\begin{array}{l}\text { Companhia Brasileira de } \\
\text { Alumínio - CBA }\end{array}$ & $\begin{array}{l}\text { Ação conjunta com Votorantim } \\
\text { cimentos em fase de comprovação } \\
\text { de viabilidade econômica }\end{array}$ & $\begin{array}{l}\text { Incorporação de resíduos do } \\
\text { processamento de bauxita em cimento }\end{array}$ & [10] \\
\hline \multirow{4}{*}{ Votoratim Metais } & Unidade de Morro Agudo & $\begin{array}{l}\text { Emprego do resíduo de beneficiamento } \\
\text { de zinco como corretivo de solo }\end{array}$ & \multirow{4}{*}{ [11] } \\
\hline & $\begin{array}{l}\text { Case Três Marias - Open } \\
\text { Inovation }\end{array}$ & $\begin{array}{l}\text { Utilização do resíduo denominado } \\
\text { cementos no processo de purificação do } \\
\text { zinco }\end{array}$ & \\
\hline & $\begin{array}{l}\text { Case Três Marias - Pozolana } \\
\text { Case Fortaleza de Minas }\end{array}$ & $\begin{array}{l}\text { Uso da lama terciária como pozolana } \\
\text { Uso de rejeito de flotação como propante }\end{array}$ & \\
\hline & Case Vazante & $\begin{array}{l}\text { Adensamento de polpa visando a } \\
\text { disposição em pilha e eliminando a } \\
\text { disposição em barragem }\end{array}$ & \\
\hline
\end{tabular}

Quadro 5. Ações dos governos no tema rejeitos de mineração.

\begin{tabular}{|c|c|c|c|}
\hline Governo & Ações & Objetivo & Referência \\
\hline $\begin{array}{l}\text { São Paulo } \\
\text { - } \quad \text { Secretaria de Energia e } \\
\text { Mineração } \\
\text { - Secretaria do Meio Ambiente } \\
\text { - } \quad \text { Secretaria de Saneamento e } \\
\text { Recursos Hídricos } \\
\text { - Casa Militar do Gabinete do } \\
\quad \text { Governador } \\
\end{array}$ & $\begin{array}{l}\text { Instituição do Grupo de } \\
\text { Trabalho - GT de } \\
\text { Barragens pela } \\
\text { Resolução Conjunta de } \\
27 \text { de novembro/ } 2015\end{array}$ & $\begin{array}{l}\text { Elaboração de Relatório de Diagnóstico e } \\
\text { Recomendações sobre Barragens de Mineração } \\
\text { do Estado de São Paulo. }\end{array}$ & [12] \\
\hline $\begin{array}{l}\text { Minas Gerais } \\
-\quad \text { FAPEMIG }\end{array}$ & $\begin{array}{l}\text { Criação da Plataforma } \\
\mathrm{R}^{3} \text { Mineral em } \\
\text { maio/2016 }\end{array}$ & $\begin{array}{l}\text { Articulação entre organizações científicas, } \\
\text { tecnológicas e industriais para repensar a gestão } \\
\text { de resíduos e rejeitos da mineração em Minas } \\
\text { Gerais e possibilitar aplicações em larga escala. }\end{array}$ & [13] \\
\hline $\begin{array}{l}\text { Federal } \\
\text { - Ministério de Minas e Energia/ } \\
\text { Secretaria de Geologia, } \\
\text { Mineração e Transformação } \\
\text { Mineral (SGM) }\end{array}$ & $\begin{array}{l}\text { Workshop Resíduos da } \\
\text { Mineração: desafios } \\
\text { para o futuro de } 22 \text { de } \\
\text { fevereiro de } 2017\end{array}$ & $\begin{array}{l}\text { Debater com entidades representativas do setor } \\
\text { mineral, os principais problemas e possíveis } \\
\text { soluções para a disposição dos resíduos sólidos } \\
\text { e rejeitos da mineração e encaminhar propostas } \\
\text { para o seu aproveitamento econômico, } \\
\text { agregação de valor, desafios tecnológicos para } \\
\text { uso futuro e redução dos passivos ambientais. }\end{array}$ & [14] \\
\hline $\begin{array}{ll}\text { Federal } \\
\text { - } \\
\text { Pinanciadora de Estudos e } \\
\text { Projetos - Finep } \\
\text { Banco Nacional do } \\
\text { Desenvolvimento Social - BNDES }\end{array}$ & $\begin{array}{l}\text { Plano de } \\
\text { desenvolvimento, } \\
\text { sustentabilidade e } \\
\text { inovação no setor de } \\
\text { mineração e } \\
\text { transformação mineral - } \\
\text { INOVA MINERAL. }\end{array}$ & $\begin{array}{l}\text { Fomento e seleção de planos de investimento } \\
\text { que contemplem o desenvolvimento tecnológico, } \\
\text { produção e comercialização de produtos, } \\
\text { processos e/ou serviços inovadores e mais } \\
\text { sustentáveis, visando ao desenvolvimento de } \\
\text { empresas e tecnologias brasileiras nas cadeias } \\
\text { produtivas da indústria de mineração e } \\
\text { transformação mineral. }\end{array}$ & [15] \\
\hline
\end{tabular}

\subsection{A Dinâmica do Setor e os rejeitos}

A dinâmica do setor de mineração é determinada por aspectos econômicos, de legislação e pelos conhecimentos e técnicas dominadas pela cadeia produtiva.

A cadeia é formada pelos seguintes elos, representados na Figura 6.

- fabricantes de equipamentos e outros insumos;

- mineradoras;

- diversos setores que absorvem o bem mineral que são incorporados em diversos produtos e processos que chegam ao consumidor final.

Dos atores que compõem essa cadeia foram identificadas 184 empresas fornecedoras de equipamentos e insumos para mineração, na sua grande maioria de capital estrangeiro, sendo que 180 delas têm escritório ou representação no Brasil. São Paulo, por se tratar do maior polo econômico do país, reúne 53,3 \% delas, enquanto 37,2 \% estão localizadas em Minas Gerais. Outros atores relevantes desta cadeia são o governo, que é o proprietário do subsolo do país e que concede 
outorga para exploração às empresas privadas, os agentes financeiros que estimulam e financiam as empresas da cadeia, as ICTs que formam mão-de-obra e desenvolvem pesquisas e tecnologias para a cadeia, e os órgãos ambientais e reguladores que possuem a tarefa de estabelecer as regras para operação da cadeia e para que o sistema opere com combinação de estímulos e restrições que incentivem o seu desenvolvimento, mas que seja capaz de retornar recursos para a sociedade como um todo.

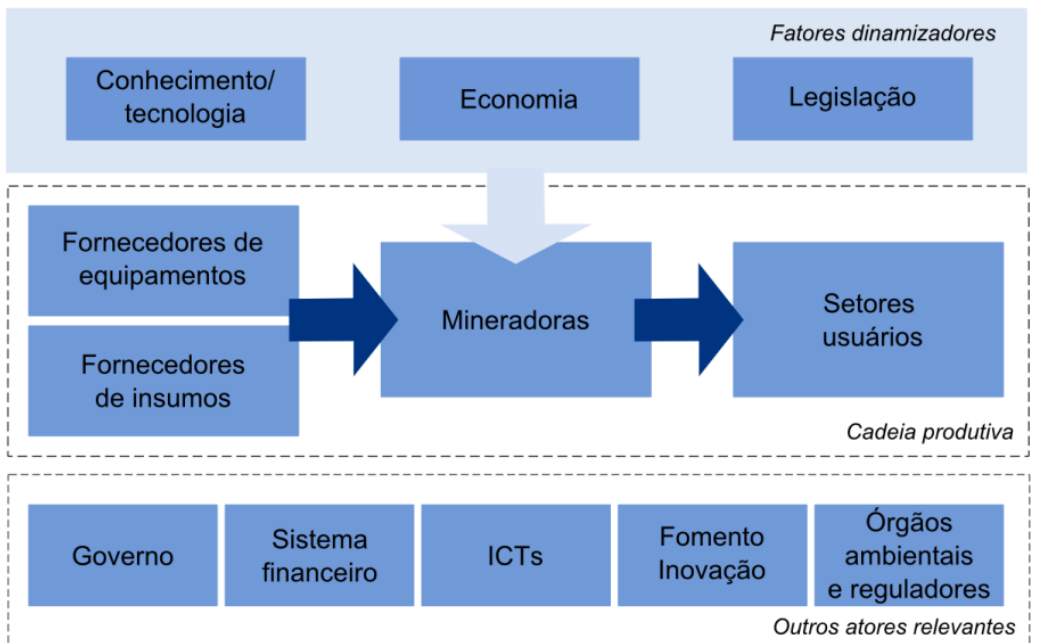

Figura 6. Atores da cadeia produtiva mineral. Fonte: Elaborado pelos autores

Em relação à cadeia de conhecimento no tema, destaca-se a oferta de vagas para graduação em engenharia de minas que passou de 292 em 2004 para 2.505 vagas atuais, caracterizando um aumento significativo da demanda por mão-de-obra. Nessa mesma linha, ressalta-se o número de grupos de pesquisa (68) nessa temática espalhados em 41 Instituições de Ciência, Tecnologia e Inovação em 17 unidades federativas. Das 95 linhas de pesquisas declaradas no tema mineração, 26 \% são diretamente relacionadas a resíduos/rejeitos.

A técnica e o conhecimento são fatores dinamizadores da cadeia, os quais permitem que os minerais sejam obtidos como recursos para serem transformados. Quanto mais conhecimento for desenvolvido em relação à etapa de pesquisa mineral, maior será o aproveitamento econômico da mina, ampliando sua vida útil e, consequentemente, contribuindo com preservação de recursos naturais. Da mesma forma, quanto maior o nível de conhecimento e de desenvolvimento tecnológico aplicado na mineração, no beneficiamento ou no processo de recuperação de rejeitos, melhor será a produtividade alcançada e maior a disponibilidade do bem mineral para aproveitamento industrial.

A dinâmica com que estas atividades de desenvolvimento são conduzidas difere grandemente entre os países com tradição em mineração. Há países que são meros usuários dos conhecimentos já desenvolvidos e disponíveis, enquanto outros investem no desenvolvimento de novas tecnologias e conhecimentos, conseguindo ampliar continuamente suas descobertas de reservas e atingindo graus de aproveitamento dos materiais que aumentam com o tempo, caracterizando-se como um processo intensamente dinâmico. Conforme apontado por Furtado \& Urias [16] as velhas técnicas abusam dos recursos naturais, mas as novas tecnologias os criam.

O setor de mineração caracteriza-se por ser intensivo no uso de conhecimentos e de capital, e como o produto obtido é de baixo valor agregado (commodity) não sendo 
possível diferenciação por produto, a economia de escala e o baixo custo de operação é que possibilitam o ganho econômico [17]. A questão principal é a empresa adotar equipamentos eficientes, mas com custo operacional baixo, obtendo competitividade com eficiência de processos.

Outro aspecto importante e que atualmente é indissociável da questão norteadora de custos é a questão ambiental e seus diversos aspectos. A regulação e a fiscalização estabelecem o patamar mínimo obrigatório de investimento para a operação das empresas, mas se as tecnologias adotadas forem economicamente viáveis, fazendo sentido econômico para o negócio, os investimentos nesta área crescem grandemente.

O cenário mundial é de valorização da sustentabilidade. No Brasil, após o último grande acidente de Mariana, a pressão por ações ambientalmente responsáveis, que diminuam a geração de resíduos e principalmente a fiscalização acerca das barragens aumentou sobremaneira.

A oportunidade e também o desafio é de construir um sistema que estimule o desenvolvimento tecnológico que seja sustentável em termos ambientais e econômicos para o setor mineral.

As empresas deveriam ser estimuladas a não apenas obter os bens minerais principais (de maior teor), mas também buscar eficiência para extrair as demais substâncias minerais presentes, mesmo em concentrações menores, e buscarem conexões de mercado para escoar esses produtos. O desafio é de conectar e estimular os vínculos entre os setores industriais que podem ser potenciais usuários desses bens minerais e de suas tecnologias.

\section{CONCLUSÕES}

O montante de recursos movimentados pelo setor mineral de US $\$ 40$ bilhões (2014) e a quantidade de empregos diretos (214.000) e indiretos (2,7 milhões) gerados evidencia a magnitude da importância da mineração para a economia brasileira.

Essa indústria tem como característica marcante os expressivos volumes e massas de materiais removidos e movimentados a partir das áreas mineradas. É consequência desse processo o volume de resíduos gerados, desde a lavra até o beneficiamento do minério. No entanto, a quantidade de resíduos gerada está diretamente ligada à natureza da jazida, aos processos de lavra e beneficiamento empregados.

Apenas 15 substâncias minerais das 70 produzidas no Brasil, dados de 2010, correspondem a cerca de $90 \%$ da produção bruta nacional, caracterizando-se também como as mais importantes geradoras de rejeito. Nove substâncias minerais, todas metálicas, geraram cerca de $85 \%$ do total de rejeitos. Apenas 15 substâncias geraram em 15 anos cerca de 4,86 bilhões de toneladas de rejeitos, sendo que as produções de ferro, ouro e fosfato representam $58 \%$ do total gerado.

Das 661 barragens de rejeitos levantadas, 249 (42,3 \%) estão associadas à produção de ferro, sendo que, em conjunto com outras 12 substâncias são responsáveis por $92,4 \%$ dos barramentos.

Com a tragédia ocorrida com o acidente da barragem da Samarco em Mariana-MG algumas grandes empresas começaram a tornar públicas suas ações no tocante aos seus esforços visando reduzir consumo de água, energia e a disposição de rejeitos dos seus processos. Da mesma forma, órgãos de governos federal e estadual têm 
promovido discussões entre os atores da cadeia sobre os desafios relativos à temática rejeitos de mineração.

Destarte das constatações aqui colocadas, é imperativa a tendência irreversível da questão da redução da geração de rejeitos, bem como o seu aproveitamento.

Os países que apresentam setor mineral dinâmico e desenvolvido são aqueles que constroem um sistema que estimula o desenvolvimento sustentável da mineração, e cujos vínculos com os setores industriais usuários dos bens minerais e de suas tecnologias são fortes. Quanto mais intensas forem essas ligações entre os diversos setores e quanto mais atuantes forem os incentivos positivos e os mecanismos legais para a geração de tecnologias, mais dinâmico, inovador e criador de recursos será o setor mineral.

Assim, a implantação do conceito de economia circular para que os bens minerais sejam absorvidos em sua totalidade é um caminho interessante a ser trilhado. Porém, as empresas para alcançar tal patamar de desenvolvimento precisam ser estimuladas e cobradas para isso. Apenas a regulação de fiscalização intensa das barragens e de restrição de liberação de área para rejeitos das agências de regulação não é suficiente para estimular a maior eficiência no uso do recurso mineral.

E no âmbito tecnológico? Nesse projeto buscou-se, também, caracterizar o estágio atual de desenvolvimento tecnológico com vistas ao aproveitamento de rejeitos de mineração, quais novos usos têm sido propostos para esses materiais, assim como quais os desafios impostos nesse contexto. Os resultados obtidos estão apresentados no artigo intitulado "Rejeitos de Mineração: Um olhar do Cenário Brasileiro - Parte II: Desenvolvimento tecnológico e novos usos", no qual os autores trazem o fechamento final das descobertas proporcionadas pelo projeto desenvolvido (Partes I e II) de forma integrada, colocando uma provocação com vistas a estimular o desenvolvimento sustentável da mineração.

\section{Agradecimentos}

Os autores agradecem ao Instituto de Pesquisas Tecnológicas do Estado de São Paulo, à Fundação de Apoio do Instituto de Pesquisas Tecnológicas do Estado de São Paulo e à Secretaria de Desenvolvimento Econômico, Ciência, Tecnologia e Inovação pelo financiamento do projeto "Mapeamento da produção de rejeitos das empresas de mineração e da maturidade das tecnologias aplicadas para sua valoração", que gerou os resultados apresentados nesse artigo.

\section{REFERÊNCIAS}

1. Araújo JLA. Resíduos da mineração. Desafios para o futuro. Ministério de Minas e Energia. 2017.

2. NRC. Minerals, Critical Minerals and the U.S. Economy. National Research Council, Washington D.C., The National Academies Press, 2008.

3. IBRAM. Informações sobre a economia mineral brasileira 2015. Instituto Brasileiro de Mineração. 2015. [acesso em: 31 de maio 2017]. Disponível em: http://www.ibram.org.br/sites/1300/1382/00005836.pdf

4. Salles C; Costa, ER. Uma visão comentada dos resíduos sólidos na mineração. IBRAM. 2015. [acesso em: 31 de maio 2017]. Disponível em: http://www.ibram.org.br/150/15001002.asp?ttCD_CHAVE=241627

5. IBRAM. Produção Mineral Brasileira (PMB). Série histórica. Instituto Brasileiro de Mineração. 2017. [acesso em: 14 de junho 2017]. Disponível em: http://www.ibram.org.br/sites/1300/1382/00006386.pdf 
6. IPEA. Diagnóstico dos resíduos sólidos da atividade de mineração de substâncias não energéticas. Relatório de Pesquisa. 2012. [acesso em: 31 de maio 2017]. Disponível em:

http://repositorio.ipea.gov.br/bitstream/11058/7702/1/RP_Diagn\%C3\%B3stico_2012.pdf

7. DNPM. Anuário mineral brasileiro. Departamento Nacional de Produção Mineral. 2010. [acesso em: 31 de maio 2017]. Disponível em:

http://www.dnpm.gov.br/dnpm/paginas/anuariomineral/arquivos/ANUARIO_MINERAL_2010.pdf

8. DNPM. Cadastro Nacional de Barragens. Departamento Nacional de Produção Mineral. 2014. [acesso em: 31 de maio 2017]. Disponível em:

www.dnpm.gov.br/assuntos/barragens/arquivos-barragens/cadastro-nacional-debarragens-de-mineracao-dentro-da-pnsb.

9. Brasil Mineral. Especial A inauguração do S11D. $n^{\circ}$ 368, janeiro/fevereiro de 2017.

10. Brasil Mineral. Empresas do ano do setor mineral. $n^{\circ} 370$, Abril de 2017.

11. ABM. Ações sustentáveis na metalurgia e mineração. Workshop de projetos inovadores na gestão de resíduos e rejeitos. Sede Usiminas - Belo Horizonte/MG. 2016.

12. São Paulo. Barragens de mineração no Estado de São Paulo. Diagnóstico e Recomendações. Governo do Estado de São Paulo. [acesso em: 14 de junho 2017]. Disponível em: http://www.energia.sp.gov.br/wp-content/uploads/2016/06/relatorio-debarragens.pdf

13. R3Mineral. Plataforma R3 mineral. Sobre a plataforma. 2017. [acesso em: 14 de junho 2017]. Disponível em: https://r3mineral.net/sobre-a-plataforma2c913970c9ca.

14. MME. Ministério de Minas e Energia. Workshop Resíduos da Mineração: desafios para o futuro. 2017. Brasília-DF. 2017.

15. Finep. Chamada pública. Financiadora de Estudos e Projetos. 2016. [acesso em: 14 de junho 2017]. Disponível em: http://www.finep.gov.br/chamadaspublicas/chamadapublica/597

16. Furtado J.; Urias, E. Recursos naturais e desenvolvimento: estudos sobre o potencial dinamizador da mineração na economia brasileira. 1 ed. São Paulo : Ed. Dos Autores/IBRAM, 2013. 311p.

17. Pavitt, K. Sectoral patterns of technical change: towards a taxonomy and a theory. Research Policy, v.13, 1984 